\title{
Degree of leanness and managerial commitment in an aerospace company
}

\begin{abstract}
Lean manufacturing is a popular concept practiced in most Japanese and western company to increase their competitiveness. However, only few of them succeed to get good result. To achieve success in implementation of lean manufacturing, company has to make changes. Managerial commitment is important in this investment. Thus, the objective of this paper is to determine the degree of leanness and managerial commitment in companies. All the information of lean manufacturing practice and role of management in the implementation were compiled from related journal, book and website. Basically, this paper refers to three published journal papers by Karlsson et al. (1996), Boyer (1996), and Soriano-Meier et al. (2002). A study was conducted in an aerospace manufacturer in Malaysia. A five-point scale questionnaire has been selected to be the study instrument. These questionnaires were distributed to 45 employees work in kitting department and 8 top management people. The results indicate that the degree of leanness and managerial commitment of the company were moderate.
\end{abstract}

Keyword: Leanness; Managerial commitment; Aerospace company 